\title{
Introduction to Lumbar Stenosis
}

By John A. Jane, M.D., Ph.D.

Two aspects of lumbar stenosis will be emphasized in this volume of Neurosurgical Focus: the controversy surrounding the need for fusion, and the type of decompression required. We will begin with four articles in which lumbar fusion is discussed; the fusion rates vary from article to article, but the indications in each series are quite similar. There appears to be agreement that segmental instability demonstrated on flexion-extension films argues in favor of fusion; the frequency with which this instability occurs, however, is not clear. Our own impression is that patients with lumbar stenosis have remarkably immobile spines. The second indication for fusion discussed in these pages is spondylolisthesis. Dr. Epstein does not believe that spondylolisthesis in itself is an indication for fusion, whereas the review of the literature by Detwiler, et al., concludes that spondylolisthesis alone is a relative indication. Dr. Epstein found fusion necessary in only 3.4\% of her patients. Coric and Branch, and Jane, et al., have suggested that either posterior lumbar interbody fusion or posterolateral fusion may be helpful in every case of spondylolisthesis.

Following the first four articles, several of the authors will discuss each other's work.

The second issue relates to the extent of decompression. Jane, et al., favor a thorough and radical removal of the offending structures. These structures are most often inferior or superior facets and are commonly the medial portion of the pedicle.

Savitz calls attention to herniated discs as a cause of symptoms. It is easy for surgeons to forget this cause in the presence of dramatically hypertrophied facets. 